\title{
Effect of Brassica oleracea L. (var, capitata) Hydroalcoholic Extract on Epithelial Layer Healing of Skin in Male Mice
}

\author{
Khayatzade J.* PhD, Barakpour E. ${ }^{1}$ BSc, Rakhshande H. ${ }^{2}$ PhD \\ *Biology Department, Sciences Faculty, Mashhad Branch, Islamic Azad University, Mashhad, Iran \\ 1Biology Department, Sciences Faculty, Mashhad Branch, Islamic Azad University, Mashhad, Iran \\ ${ }^{2}$ Pharmacology Department, Medicine Faculty, Ferdowsi University, Mashhad, Iran
}

\begin{abstract}
Aims: Wound healing is a complex physiological process involves a series of successive stages of hemostasis, inflammation, proliferation, and regeneration. This study aimed to investigate the effect of hydroalcoholic extract of Brassica oleracea L. (var. capitata) leaves in comparison with Phenytoin on epithelial layer healing and the holes in the skin of mice.

Materials \& Methods: This study was done on 40 male NIH Mice between 2530 gr. Animals were randomly divided into 4 groups $(n=10)$. Negative control group received saline, positive control group administrated with $1 \%$ Phenytoin and treated groups received $10 \%$ and $20 \%$ hydroalcoholic extract twice a day until closing holes. Macroscopic and microscopic analysis was performed on days 1, 4, 7, 12 and 15. Statistical analysis was done by SPSS 16 software and Tukey test.

Findings: A significant reduction was observed in average size of holes in 20\% hydroalcoholic extract treated group compared to the negative control $10 \%$ extract at day $7(\mathrm{p}=0.001)$. There was a significant reduction in average size of holes in $20 \%$ extract group compared to $10 \%$ extract and negative control groups at day 12. $(\mathrm{p}=0.007)$. The skin holes in $20 \%$ extract group were closed earlier than the other groups. Epithelial thickness was increased in 20\% extract group from 7 th day the much faster than other groups.

Conclusion: Brassica oleracea L. (var. capitata) has the same effect of phenytoin in healing of rapid closure of holes and proliferation of epithelial cells.
\end{abstract}

\author{
Keywords \\ Re-Epithelialization [http://www.ncbi.nlm.nih.gov/mesh/68062326]; \\ Skin [http://www.ncbi.nlm.nih.gov/mesh/68012867]; \\ Mice [http://www.ncbi.nlm.nih.gov/mesh/68051379]; \\ Epithelium [http://www.ncbi.nlm.nih.gov/mesh/68004848]
}


تعامل بين انواع مختلف سلولها، بروتئينهاى ساختمانى،

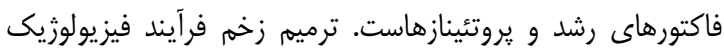

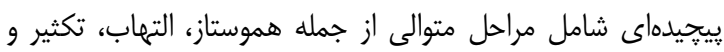

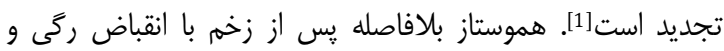

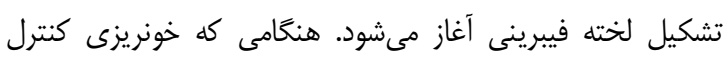

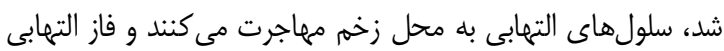

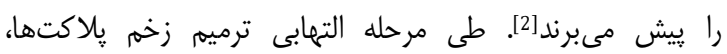

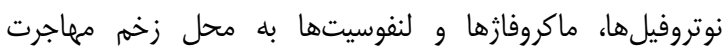

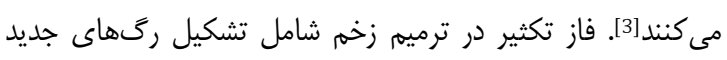

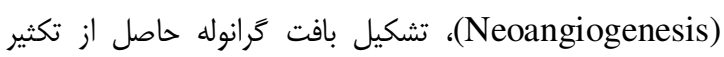
فيبروبلاستها و تشكيل مجدد اييدرم (Reepithelialization)

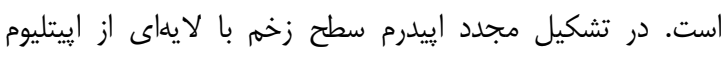

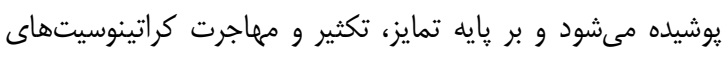

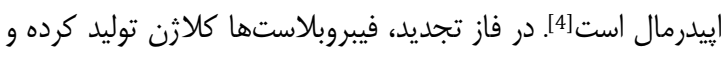

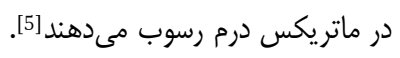

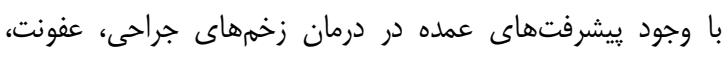

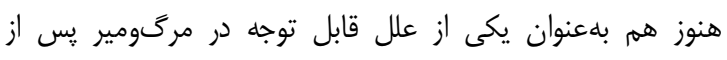

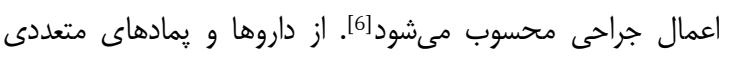

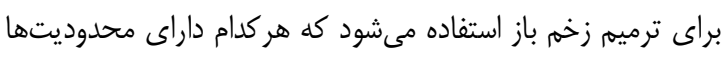

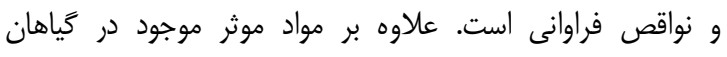

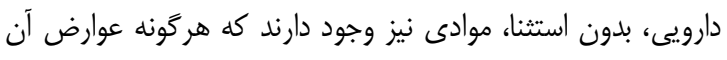

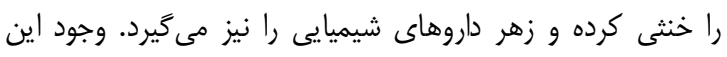

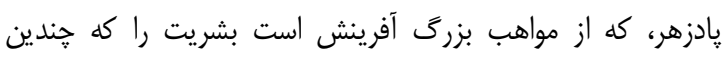

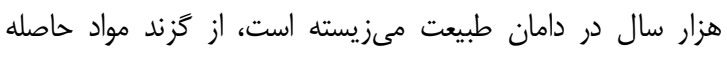

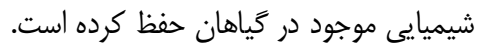

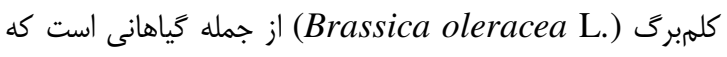

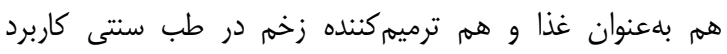

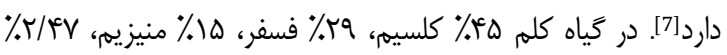

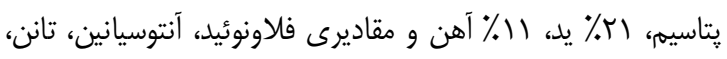

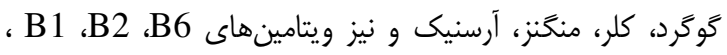

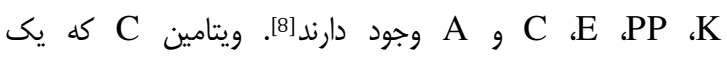
آنتىاكسيدان است، بهعنوان كوفاكتور در تشكيل يروكلازن نقش

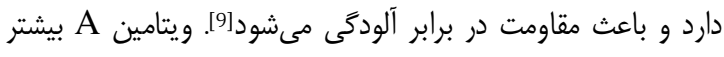

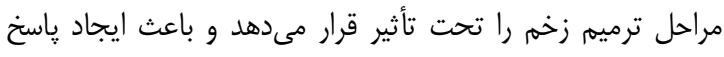

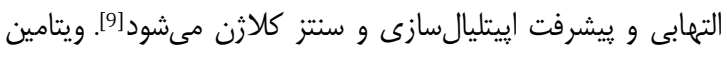
E

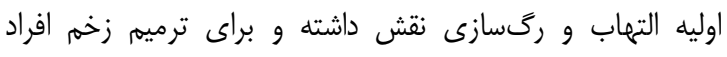

$$
\text { ديابتى سودمند است [9]. }
$$

كلم قرمز (Brassica oleracea L. var. capitata) بلتازتى سونى

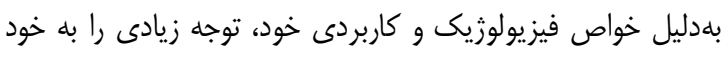

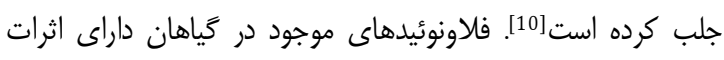

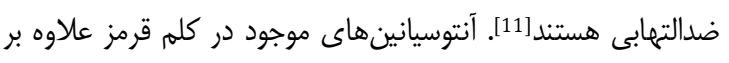

اثر عصاره هيدروالكلى كلم قرمز بر التيام لايه

\section{إيتليال يوست در موشهاى نر هيدر}

PhD " جينا خياطزاده

كروه زيستشناسى، دانشكده علوم، واحد مشعه، دانشخاه آزاد اسلامى، مشهد، ايران

اليهام بركيور BSc إيران

كروه زيستشناسى، دانشكده علوم، واحد مشهل، دانشخاه آزاد اسلامى، مشهد، ايران

حسن رخشنده PhD كروه فارماكولوزى، دانشكده يزشكى، دانشخاه فردوسى، مشهل، ايران

: ترميم زخم فرآيند فيزيولوزيك بيجيديداى شامل يك سرى

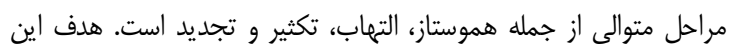

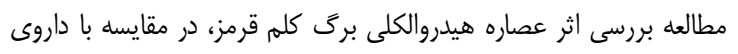

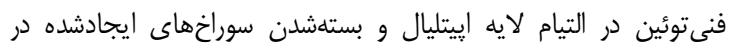

$$
\text { يوست موش سورى نر بود. }
$$

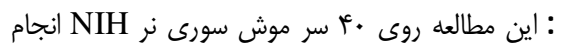

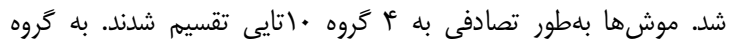

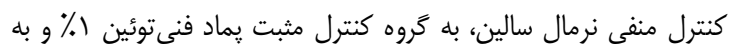

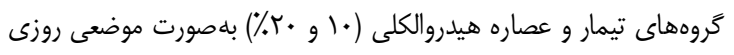

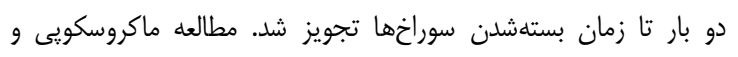

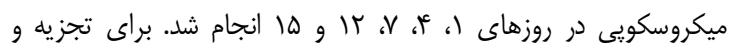

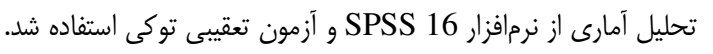

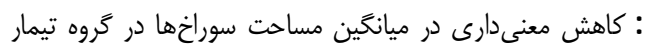

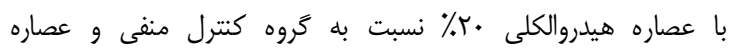

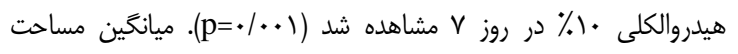

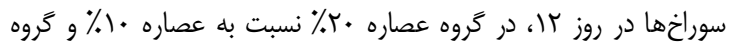

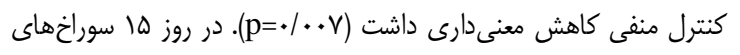

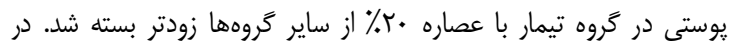

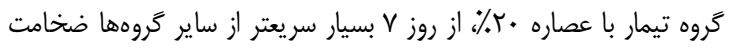
إييتليال افزايش يافت. : كلم قرمز در التيام زخم يعنى بستهاشدن سريع سوراخهاى

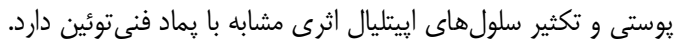

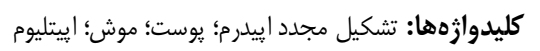

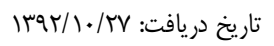

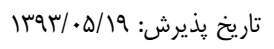

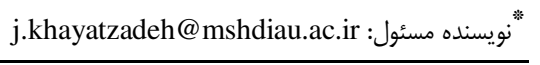

مقدمه

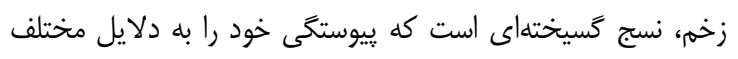

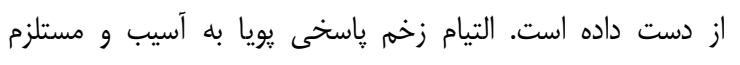

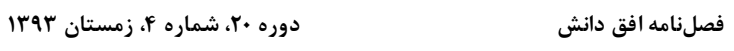




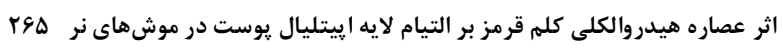

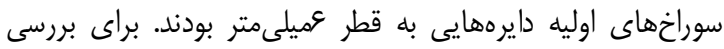

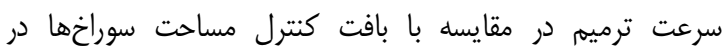

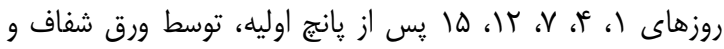

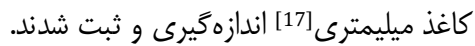

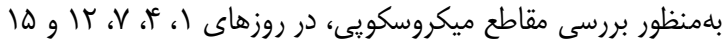

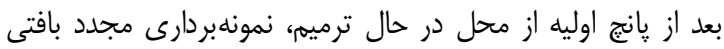

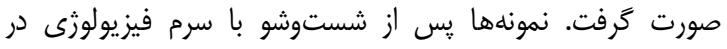

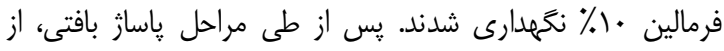

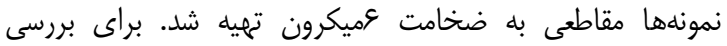

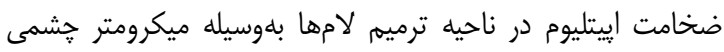

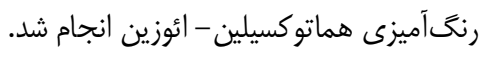

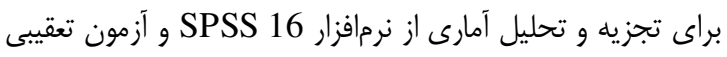
توكى استفاده شد.

يافتهها

تفاوت معنىدارى بين گروههاى كنترل و تيمار از نظر شواهد ماكروسكويى در روز 1 و أ يس از ايجاد سوراخ، وجود نداشت.

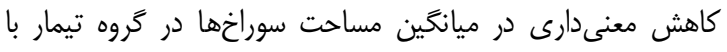

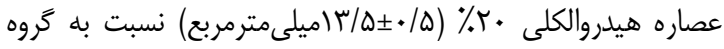

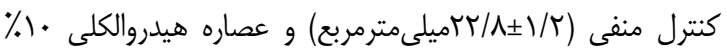

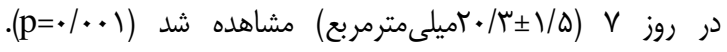

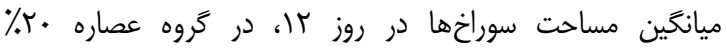

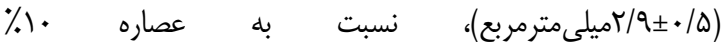

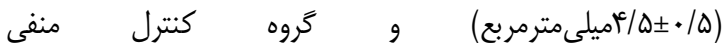

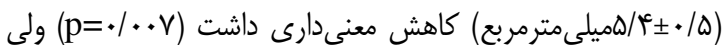

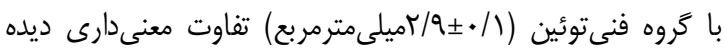

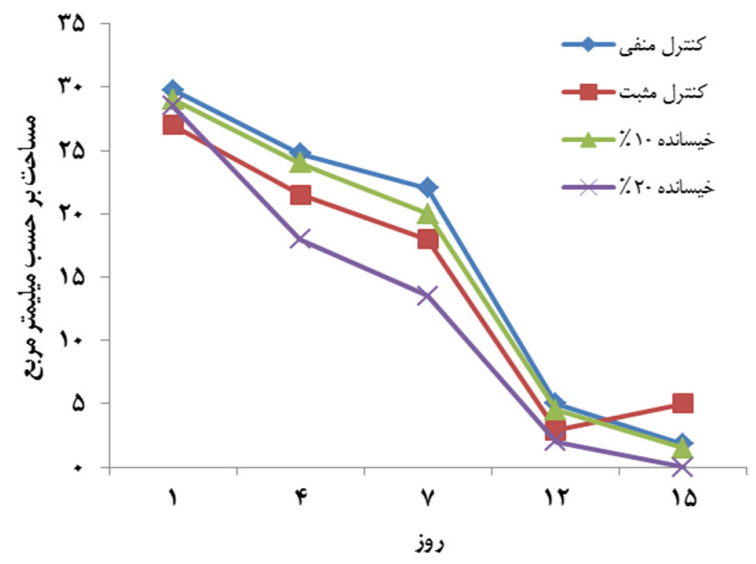

نمودار ( ) مقايسه خطى مساحت سوراخها (ميلىمترمربع) طى بازه ها روزه در كروههاى مورد مطالعه
داشتن خواص رنكى، در بسيارى از عملكردهاى فيزيولوزيك از

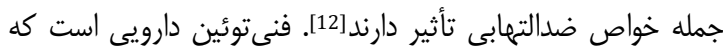

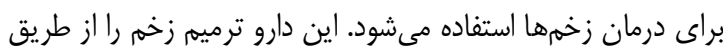

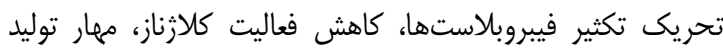

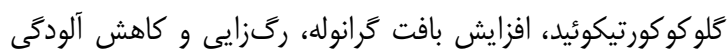
ميكروبى ميسر مىسازد [13ن]. هدف اين مطالعه بررسى اثر عصاره هيدروالكلى برى مائل كلم قرمز، در

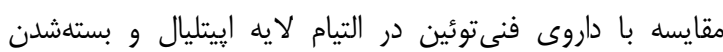
سوراخهاى ايجادشده در يوست موش سورى نر بود.

\section{مواد و روشها}

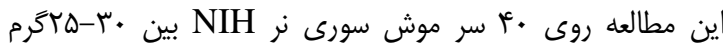

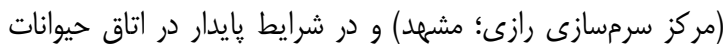

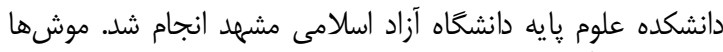

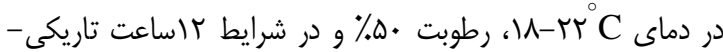

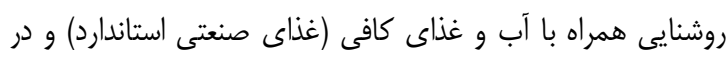

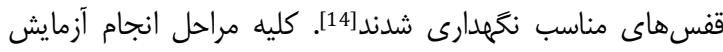

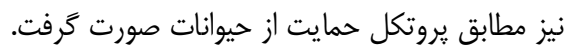

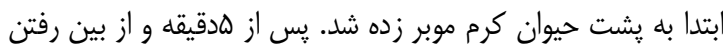

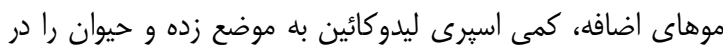

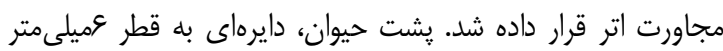

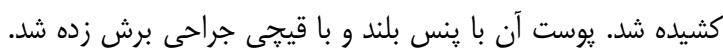

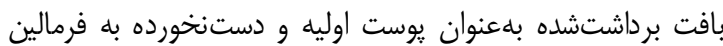

منتقل شد. قبل و بعد از برش موضع با بتادين ضدعفونى شد.

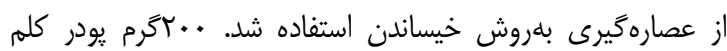

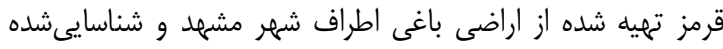

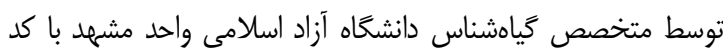

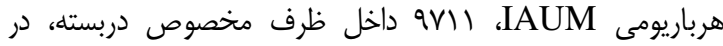

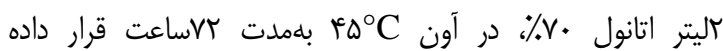

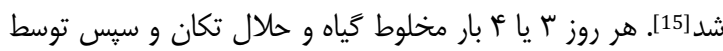

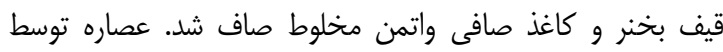

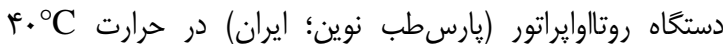

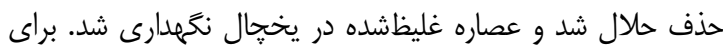

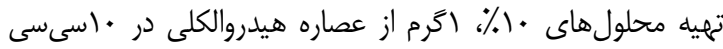

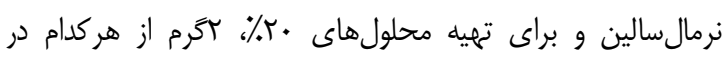
• آسىسى نرمال سالين حل شدند.

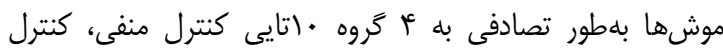

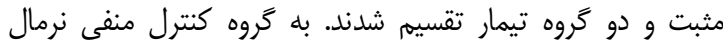

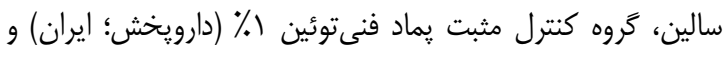

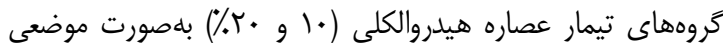

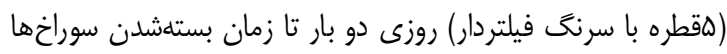
تجويز شد[16]. 


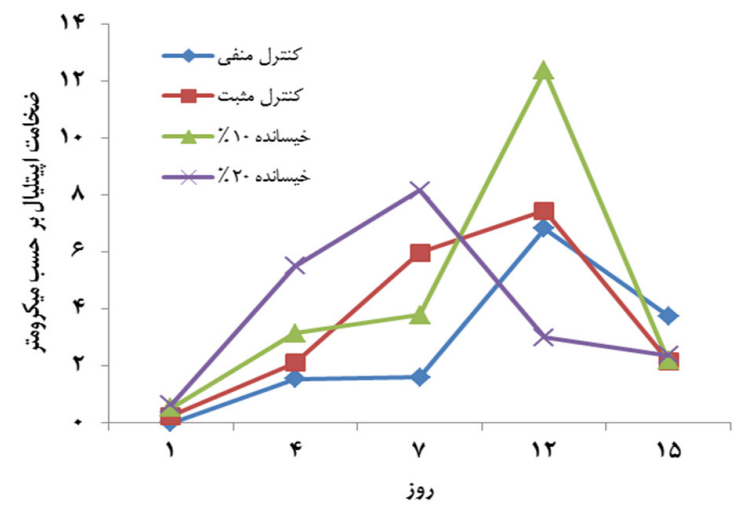

نمودار ץ) مقايسه ضخامت إيتليال (ميكرومتر) طى بازه ها روز در كروههاى مورد مطالعه
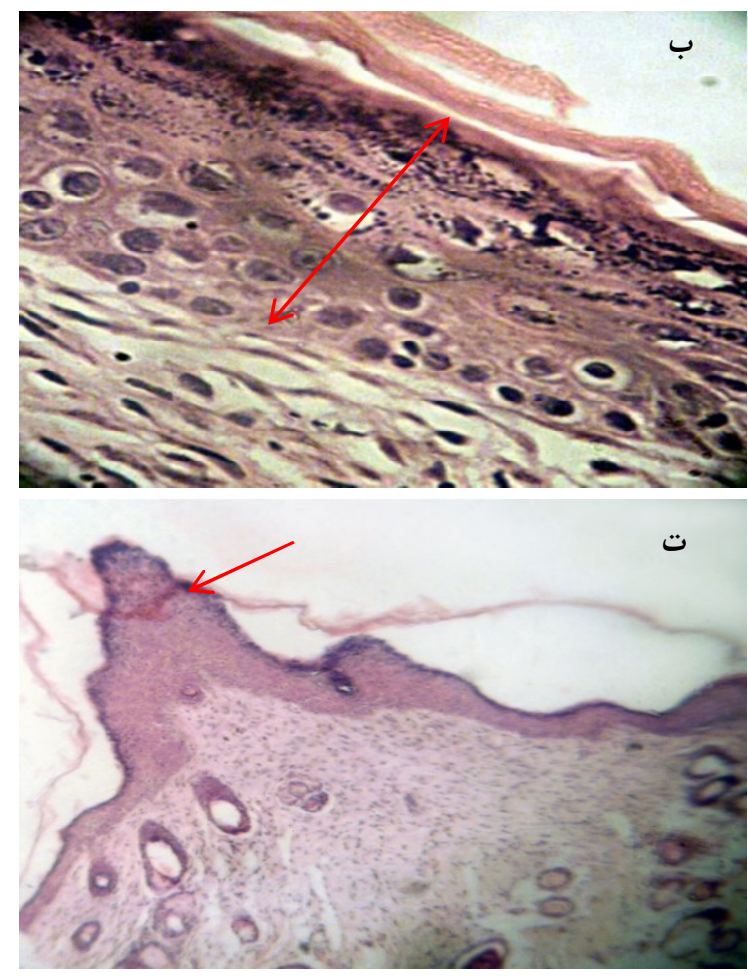

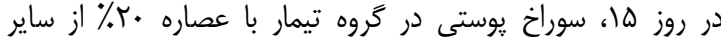

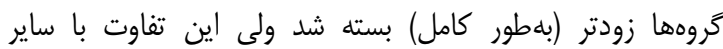

كروههاى تيمار و كنترل معنى دار نبود (نمودار (1).

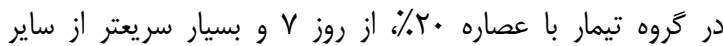
گروهها بهخصوص كنترل منفى (شكل ال، الف)، ضخامت إيتليال

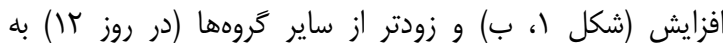

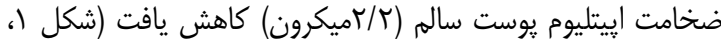

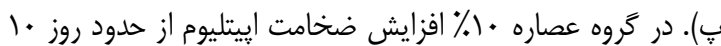

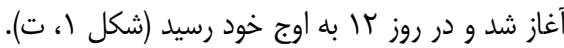

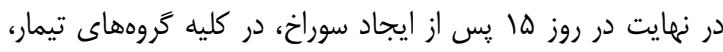
ضخامت إيتليوم مشابه با يوست سالم و تيمار با فنىتوائين بود. اما كروه كنترل منفى داراى تاخير بود (نمودار r).

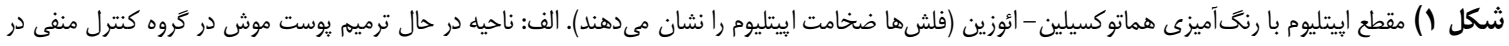

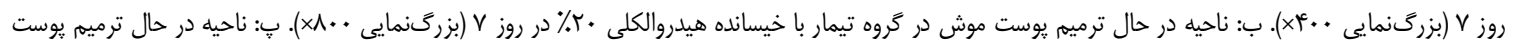

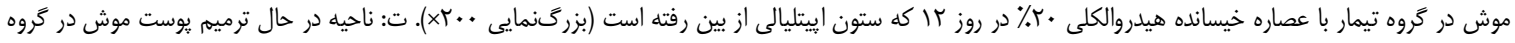

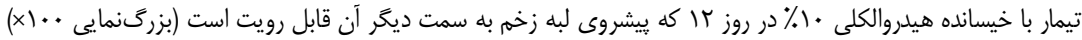

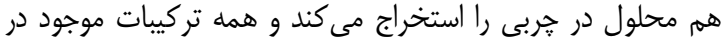

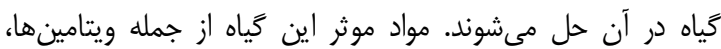

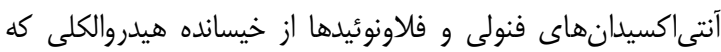

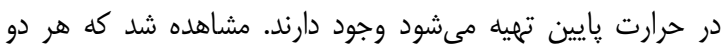

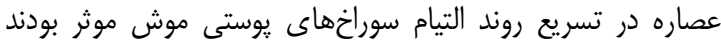

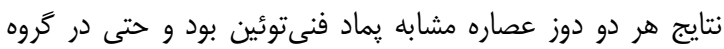

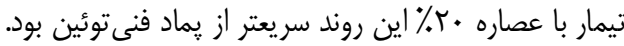
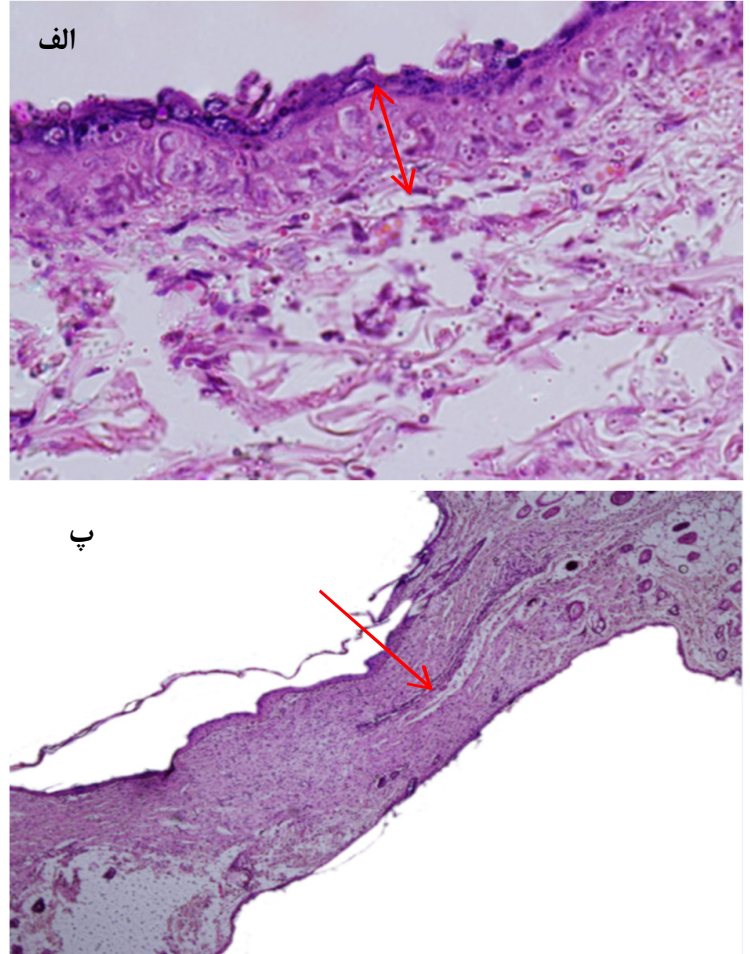


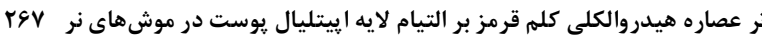

$$
\begin{aligned}
& \text { نتيجه كيرى } \\
& \text { كلم قرمز در التيام زخم يعنى بستهشدن سريع سوراخهاى يوستى و } \\
& \text { تكثير سلولهاى اييتليال اثرى مشابه با پِماد فنى توئين دارد. }
\end{aligned}
$$

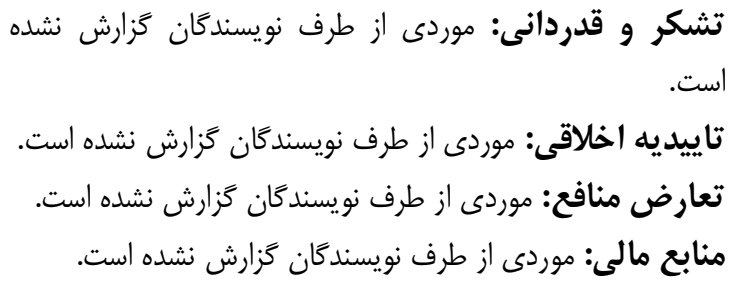

\section{منابع}

1- Oryan A, Zaker SR. Effects of topical application of honey on cutaneous wound healing in rabbits. Zentralbl Veterinarmed A. 1998;45(3):181-8.

2- Campos AC, Groth AK, Branco AB. Assessment and nutritional aspects of wound healing. Curr Opin Clin Nutr Metab Care. 2008;11(3):281-8.

3- Sauermann K, Jaspers S, Koop U, Wenck H. Topically applied vitamin $\mathrm{C}$ increases the density of dermal papillae in aged human skin. BMC Dermatol. 2004;4:13.

4- Tanaka T, Horiuchi G, Matsuoka M, Hirano K, Tokumura A, Koike T, et al. Formation of lysophosphatidic acid, a wound-healing lipid, during digestion of cabbage leaves. Biosci Biotechnol Biochem. 2009;73(6):1293-300.

5- Heo HJ, Lee CY. Phenolic phytochemicals in cabbage inhibit amyloid b protein-induced neurotoxicity. LWT Food Sci Technol. 2009;39(4):331-7.

6- Mirzai N, Vatanchian M. Effect of aqueous extract of (Olea europaea L.) on skin wound healing in mice. Q J Dev Biol. 2010;2(9):7-14

7- Schreml S, Szeimies RM, Prantl L, Landthaler M, Babilas P. Wound healing in the 21st century. J Am Acad Dermatol. 2010;63(5):866-81.

8- Lin JY, Li CY, Hwang IF. Characterisation of the pigment components in red cabbage (Brassica oleracea L. var.) juice and their anti-inflammatory effects on LPSstimulated murine splenocytes. Food Chem. 2008;109(4):771-81.

9- Burns JL, Mancoll JS, Phillips LG. Impairments to wound healing. Clinics Plast Surg. 2003;30(1):47-56.

10- Posten W, Wrone DA, Dover JS, Arndt KA, Silapunt S, Alam M. Low-level laser therapy for wound healing, mechanism and efficacy. Dermatol Surg. 2005;31(3):33440.

11- Ruiz P.A, Braune A, Holzlwimmer G, Qu uintanillaFend L, Haller D. Quercetin inhibits TNF-induced NFkappaB transcription factor recruitment to proinflammatory gene promoters in murine intestinal epithelial cells. J Nutr. 2007;137(5):1208-15.

12- Jia Y, Zhao G, Jia J. Preliminary evaluation: the effects of Aloe Ferox Miller and Aleo arborescens Miller in wound healing. J Ethnopharmacol. 2008;120(2):181-9.

13- Suguna L, Sivakumar P, Chandrakasan G. Effects of Centella asiaticaextract on dermal wound healing in rats. Indian J Exp Biol. 1996;34(12):1208-11.
افزايش ركَزايى سرعت التيام زخم را افزايش مى دهد، زيرا به دنبال

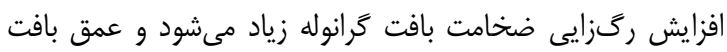

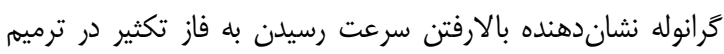

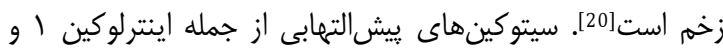

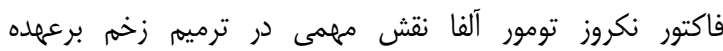

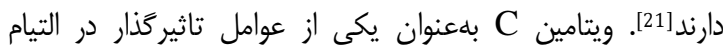

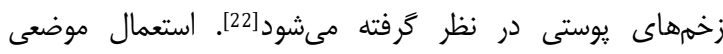

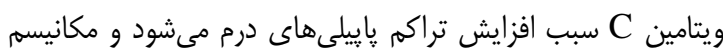

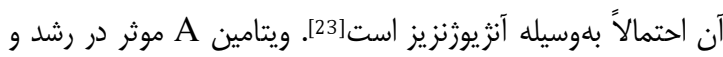
نمو بافت يوششى، افزايش بيوند عرضى كلاثن و افزايش استحكام

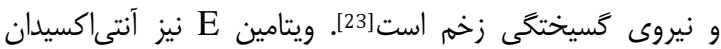

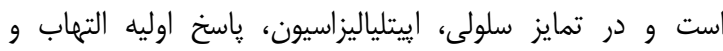

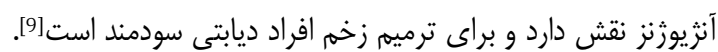

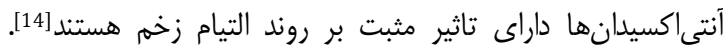
تاثير مثبت كلم نيز مىتواند ناشى از آنتىاكسيدانهاى آن باشد. كلم

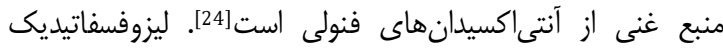
اسيد از تركيبات موثر در كلم و نوعى ميانجى لييبدى است كه نقش

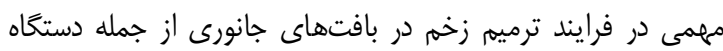

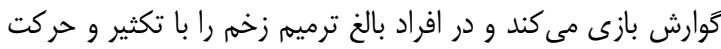

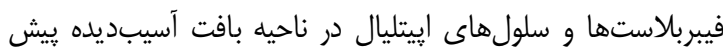
مىبرد[25]. - مئما.

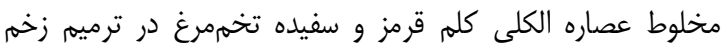

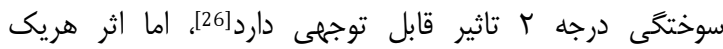

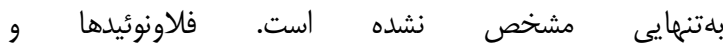

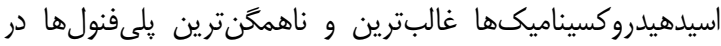

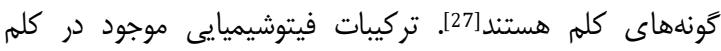
عملكردهاى متفاوتى دارند. آنها از استرسهاى اكسيداتيو جلوكيرى فئري

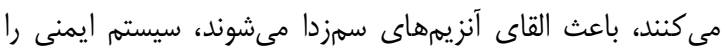
تحريك مى كنند، خطر ابتلا به سرطان و تكثير سلولهاى إنهاى سرطانى

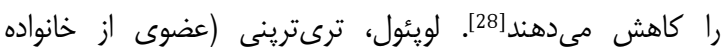
فيتواسترول) است كه در كلم سفيد، فلفل سبز، توتفرنكى، زئن زيتون،

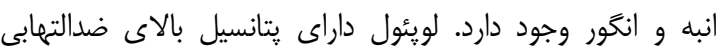

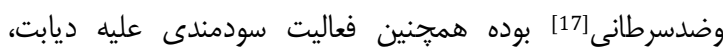

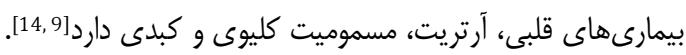

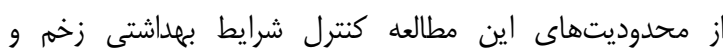

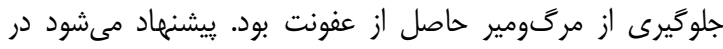

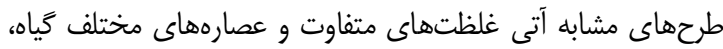
يودر كياه يا يمادهاى حاصل از ادغام اين تركيبات با مواد پايه مانند

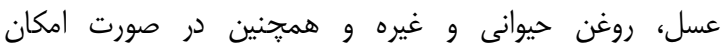

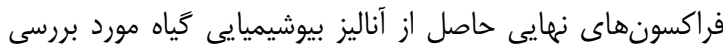

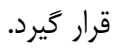


effects. Food Chem. 2008;109:771-81.

22- Yu N, Zhai X, Xin C. An experimental studyof rabbits' wound repair by amniotic carriercomplex membrane containing bFGF andvitamin $\mathrm{C}$ and loaded withBMSCs. Zhongguo Xiu Fu Chong Jian Wai Ke Za Zhi. 2008;22(12):1495-500. [Chinese]

23- Hemmati AA. Effects of Scrophularia striata Extract on wound Healing in Rabbit. J Ilam Univ Med Sci. 2010;17(4);9-16.

24- Bahorun T, Luximon-Ramma A, Crozier A, Arioma OI. Total phenol, flavonoid, proanthocyanidin and vitamin $\mathrm{C}$ levels and antioxidant activities of Mauritian vegetables. J Sci Food Agric. 2004;84(12):1553-61.

25- Samuelsen AB, Westereng B, Yousif O, Holtekjlen AK, Michaelsen TE, Knutsen SH. Structural features and complement-fixing activity of pectin from three Brassica oleracea varieties: white cabbage,kale and red kale. Biomacromolecules. 2007;8(2):644-9.

26- Hasanzadeh GR, Mehdikhanloo N. The effect of compound of Brassica Oleracea L. and egg-white on burn wound healing in rat. Q $\mathrm{J}$ Sabzevar Univ Med Sci. 2005;11(4):6-12.

27- Hübner G, Brauchle M, Smola H, Madlener M, Fässler $\mathrm{R}$, Werner S. Differential regulation of pro-inflammatory cytokines during wound healing in normal and glucocorticoid-treated mice. Cytokine. 1996;8(7):548-56.

28- Cartea ME, Francisco M, Soengas P, Velasco P. Phenolic compounds in Brassica vegetables. Molecules. 2011;16(1):251-80.
19A T جينا خياطزاده و همكاران

14- Paiva LA, de Alencar Cunha KM, Santos FA, Gramosa NV, Silveira ER, Rao VS. Investigation on the wound healing activity of oleoresin from copaifera langsdorffi in rats. Phytother Res. 2002;16(8):737-9.

15- Townsend Jr CM, Beauchamp RD, Evers MD BM, Mattox MD L. Sabiston textbook of surgery: The biological basis of modern surgical practice. $19^{\text {th }}$ ed. New York: Saunders; 2012.

16- Krishnan P. The scientific study of herbal wound healing therapies: Current state of play. Curr Anaesth Crit Care. 2009;17(1-2):21-7.

17- Chithra P, Sajithlal GB, Chandrakasan G. Influence of Aloe vera on the glycosaminoglycans in the matrix of healing dermal wounds in rats. $J$ Ethnopharmacol. 1998;59(3):179-86.

18- Jarahi M, Zahedi khorasani M, Ajorloo M, Taherian A. Local effect of Aloe barbadensis Miller gel on skin incisional wound healing in Rat. J Gorgan Univ Med Sci. 2009;11(1);13-7.

19- Allah Tavakoli M, Vazirinejad R, Ansari Jaberi A, Negahban T, Mashayekhi H, Nazari M, et al. Effect of Teucrium polium extract on skin wound healing in rat. Med J Hormozhan Univ. 2012;16(1):17-24.

20- Henriques A, Jackson S, Cooper R, Burton N. Free radical production and quenching in honeys with wound healing potential. J Antimicrob Chemother. 2006;58(4):773-7.

21- Jin-Yuarn Lin, Chia-Yuan Li, I-Farn Hwang. Characterisation of the pigment components in red cabbage (Brassica oleracea L. var.) juice and their anti-inflammatory 